\title{
EL HORMIGÓN COMO MATERIA MOLDEABLE EN LA CONSTRUCCIÓN DE ESCULTURAS
}

\author{
(CONCRETE AS CASTING MATERIAL IN SCULPTURAL CONSTRUCTION)
}

Jesús Molina, Escultor

ESPAÑA

Fecha de recepción: 31-I-96

$680-6$

\section{RESTMEN}

lil hormigón armado, que trajo consigo una revolución en el campo de la arquitectura, tanto en su componente estructural como en su morfologia, no está exento de rechazos a causa de su rudeza, que todavia hoy persisten en aquellas personas que atienden más a aspectos particulares que al análisis glohal de una obra.

Iil hormigón ha aproximado las formas arquitectónicas a la composición escultórica y viceversa. Puede emocionarnos más la contemplación de un magnífico puente cuyo arco se eleva a gran altura dibujando una linea en el espacio, que una escultura realizada en ricos materiales, si bien en el primer caso hay un componente de ingenio en su

construcción, éste hace su aparición después de que nuestros sentidos han registrado su primera emoción.

\section{SUMMARY}

Reinforced concrete, which has revolutionized architecture both in its structural components and in its morphology, still causes some rejection, because of its harshness, on those who have more consideration for singular aspects than for the global analysis of the work.

Concrete links together architectural form and sculptural composition. The sight of a bridge whose arch draws a magnificent line high in the space, can wake up deeper emotional feelings than a sculpture made out of the richest materials. In the first case there is indeed an ingenious component in its construction, but we realize about it after our senses have recorded that previous emotion.
La muestra más evidente de este parentesco arquitectura-escultura en cuanto a sus formas nos lo ha dado Le Corbusier y fue, precisamente, utilizando el hormigón como un material pastoso que se moldea, al igual que el fundidor vierte el metal fluido en el interior de un molde.

Le Corbusier dejó el hormigón visto, hizo que la carencia de revestimiento diera dignidad propia a la forma. Creo que su obra contribuyó a perder el miedo para utilizar el hormigón por escultores, que vieron este material como idóneo para sus composiciones.

Si bien es cierto que las vanguardias del arte plástico emplearon todo tipo de materiales para la realización de sus obras, también es cierto que hasta los años cincuenta no utilizan el hormigón como material constructivo, prime- ro por el carácter constructivista, lineal y ligero de sus obras, utilizando preferentemente perfiles y planchas de acero y segundo por las cualidades de la piedra frente al hormigón. En definitiva, el escultor no proyectaba sus obras pensando en este material.

Por fin su integración en la arquitectura por medio de relieves en grandes fachadas de edificios públicos, la realización de grandes esculturas aplicando las nuevas tecnologías y el desarrollo de sus cualidades plásticas para planificar espacios abiertos y plazas públicas, han acercado este material hasta nuestros días con la consiguiente colaboración de artistas, arquitectos e ingenieros.

Sería injusto pasar por alto la influencia que tuvieron los arquitectos Breuer, Le Corbusier, Niemeyer, Tange, Scarpa 
y muchos otros que experimentaron con este material, abriendo el camino para una nueva y atractiva plástica.

En cuanto a la nobleza o no de los materiales, creo dificil contraponer la belleza de una composición construida en hormigón, con la definición de este material como nonoble. ¿Cómo se puede clasificar de material rudo y feo el empleado por Le Corbusier en la capilla de Ronchamp, o el empleado por Carlo Scarpa en el cementerio Brion en San Vito de Altivole? De esto se deduce que el acto creativo del hombre está por encima de los materiales y aún reconociendo que las obras de urbanismo raramente se acercan a la belleza, esto es más culpa del concepto estético del hombre que de los materiales.

\section{La tecnología del hormigón aplicada a la creación artística}

El hormigón es un compuesto artificial de arena, grava y cemento como aglomerante. La cualidad que más aporta al escultor es el carácter pastoso de su masa y su lento fraguado; esto hace que todas las formas susceptibles de ser moldeadas se puedan realizar en este material. Generalmente los escultores que han elegido este material, son aquéllos cuyas composiciones son de carácter geométrico y por tanto arte abstracto, arte de nuestros dias.

El escultor puede elegir la textura de su superficie, por medio del grosor de los áridos, elección de la superficie de los elementos que componen el encofrado, el color de los áridos o coloreando la masa. Pero si lo prefiere, antes de finalizar el tiempo de fraguado y retirado el encofrado, el escultor puede lavar su superficie, arrancándole la piel y dejando al descubierto una magnífica textura pétrea.

Las intenciones del arquitecto y del escultor son bien diferentes; al primero le preocupa, sobre todo, si su construcción es correcta para soportar las cargas que le han sido asignadas. Al segundo, que en esos problemas ha sido asistido por un arquitecto o ingeniero, le interesa más la terminación de la superficie, lo que él quiere que nuestros sentidos perciban y que esté en armonía con su Gestalt. Por eso el escultor elige el material del encofrado que dejará grabada su textura en la superficie de su obra. También utiliza el cemento blanco como componente estético para diferenciarlo del color grisáceo-verdoso.

Algunos autores utilizan en sus composiciones combinaciones de hormigón armado con estructuras metálicas de acero o bronce.

El relieve es la técnica más usada en la decoración de edificios; son las primeras relaciones arquitecto-escultor en la misma obra. Anteriormente, el arquitecto veía el relieve como un añadido a su obra, y tenía razón de no existir una relación de trabajo entre los dos artistas. La perfecta integración del relieve con el muro se logra mediante el moldeado de los dos elementos al mismo tiempo. La uniformidad constructiva queda asegurada, nuestra mirada se desliza a lo largo y ancho del muro, percibiendo todo como una sola obra.

Un caso especial es la incrustación de placas de vidrio en el muro a la manera de las vidrieras emplomadas que cierran los huecos de luz en los templos clásicos. Estas placas, de dos o tres centímetros de espesor, son instaladas antes de moldear el hormigón, lo que hace que su adherencia y sujeción sea perfecta. El efecto producido de luz y color contrasta con la percepción pétrea y pesada del hormigón.

Las composiciones de color geométrico-cinéticas de Victor Vasareli (Hungría, 1908), le indujeron a su autor proyectarlas para grandes superficies, utilizando el hormigón coloreando en su masa. No realizó muchas obras pero sí trabajó en numerosas propuestas para demostrar las posibilidades de esta técnica, que se pueden ver en su fundación de Aix-en-Provence. Sus obras, $500 \mathrm{~m}^{2}$, de fachada en el Ayuntamiento de Maubenge, Francia y otro, de $600 \mathrm{~m}^{2}$, con una modulación en blanco y negro, en la Facultad de Ciencias de Marsella St.Jerome.

Otras de las técnicas relacionadas con el color la realizó Alicia Penalba (Argentina 1918) y consistía en aplicar con una llana capas de mortero coloreadas en la masa, sobre un cuerpo de hormigón ya construido. Grupo de esculturas Universidad de Saint-Gall, Suiza.

Betongrave, palabra sueca con la que definieron Erling Viksjo, arquitecto y Suerre Lystad, ingeniero, una nueva técnica del hormigón, consiste, fundamentalmente, en rellenar el encofrado de piedras con las calidades y colores deseados, representando el $75 \%$ del volumen; sometiendo el encofrado a vibraciones para conseguir el máximo de densidad se inyecta cemento muy líquido a 5 atmósferas de presión y añadiéndole al cemento un producto químico para evitar su contracción. Uná vez retirado el encofrado, el grabado sobre su superficie de las líneas de un dibujo por medio de un chorro de arena a presión, deja al descubierto las piedras que contribuyen a la calidad estética del resultado final.

Así, el escultor Sueco Carl Nesjar le comunicó a Picasso esta técnica y los dos trabajaron juntos alrededor de una veintena de obras a partir de 1956.

Algunos artistas quisieron ocultar el aspecto externo del hormigón pintando su superficie. En el Museo KrollerMuller de Otterlo, Holanda, Jean Dubuffet realizó una construcción horizontal de $20 \times 30 \mathrm{~m}$ con un árbol incluido de $8 \mathrm{~m}$ de altura; todo está construido en hormigón armado, después cubierto de cemento blanco y posteriormente pintado con poliuretano blanco.

También en México, González y Goeritz dieron esta 
terminación al hormigón pintando su superficie. Goeritz realizó en 1970 en la Ciudad de México la Pirámide de Mixcoac, composición de 114 módulos prefabricados y pintados en blanco.

\section{El relieve}

A lo largo de toda la historia el arquitecto necesitaba de los artistas para la decoración de los paramentos externos de sus edificios, que hoy podemos contemplar y admirar con sus maravillosos trabajos de talla en piedra. Estos trabajos artísticos son ajenos a la construcción del muro.

A diferencia de la arquitectura clásica, el arquitecto contemporáneo, como fruto del diálogo con el escultor, ha integrado el relieve en el muro utilizando el mismo material y construyéndolo al mismo tiempo, perdiendo el relieve parte de su identidad propia y objetual para generar una sola identidad con el muro. Ya no hay un relieve "colgado" del muro, los dos elementos forman una sola obra.

El escultor puede imprimir en la superficie aquella huella que deje el material elegido para el encofrado. La madera ha sido el material más usado para la fabricación del molde, dejando el dibujo de sus vetas y su grano impreso en la superficie moldeada; debido a la propiedad higroscópica de la madera que, por medio del cemento húmedo, hace resaltar y diferenciar la madera de primavera y otoño sobre la superficie.

El escultor Fritz Wotruba (Viena, 1907) realizó un largo friso de figuras humanas en el muro de un edificio público de Viena.

Quizás sea Odon Koch (Zurich, 1906)el escultor que mejor ha integrado sus relieves en el muro de hormigón; sus composiciones geométricas dialogan perfectamente con las formas arquitectónicas y, en algunos casos, establece una continuación del diálogo mediante la instalación de una escultura próxima al muro-relieve.

Sus obras más relevantes utilizando esta técnica son:

Iglesia Reformista de Biel - Bozinger (Suiza, 1965).

Instituto Bacteriológico, Universidad de Zurich, 1959.

Casa Hoffman - La Roche. Basilea, 1968

Aún reconociendo que la colaboración entre artistas y escultores ha sido escasa, hay que destacar los trabajos de O.H. Hajeek en Alemania, relieves policromados. Haris Barron en Estados Unidos. Lars England en Suecia, Estación de Televisión en Orebro. En Guadalajara, México, fue Luis Tomasello quien realizó el Mural Cromático de S.Pedro.

\section{Escultura}

Desde hace algún tiempo la creencia tradicional de que la escultura estaba restringida al uso del mármol y el bronce han sido abandonadas.

Los artistas contemporáneos han cambiado de materiales, el constructivismo trajo consigo el empleo de perfiles de acero o aluminio, los mimalistas americanos emplearon materiales industriales de todotipo, incluso la construcción requería de mano especializada, otros utilizaron materiales sintéticos y cómo no, el hormigón armado.

Alguien definióla arquitectura como construcción + poesia, y esto mismo se acentúa más en la escultura, por estar exenta de la funcionalidad de la primera.

Resulta difícil extrapolar conceptos de la arquitectura a la escultura, pero de sobra es conocido que el concepto de espacio (no de su funcionalidad) es inherente a estas dos artes. Tan insensato puede ser hacer habitable una escultura como que un edificio se empeñe en ser una escultura, aunque algunos arquitectos en los cincuenta trabajaron con mucho acierto sobre este concepto.

Si existe un nexo común entre estas dos artes, éste es el espacio vacío que pretenden ocupar, pero que unos y otros persiguen con fines diferentes y que da al escultor más libertad de creación para manipular este espacio. Sus límites son su propio concepto de lo estético y por tanto de la belleza, el conseguir lo que persigue y que por fortuna nunca termina de alcanzar.

Pero no todos los escultores utilizan el espacio de la misma manera y no me refiero al estilo de sus obras, sino en cómo ocupan ese espacio.

En 1917, Theo Van Doesburg justificaba sus teorías sobre una nueva forma de hacer "con la necesidad de destruir la plástica del Barroco, la morfoplástica, porque era incapaz de expresar el espíritu de su tiempo" (Principios del Nuevo Arte Plástico, 1919).

El austriaco Fritz Wotruba (Viena, 1907) es uno de los grandes escultores de este siglo, abstrae y sintetiza la figura humana convirtiéndola en un conjunto de prismas y cilindros, que favorece su conversión al servir de modelo para su moldeado en hormigón, en este caso el modelo es una obra terminada tallada en piedra; aunque la reproducción exprese fidelidad a la piedra, inevitablemente ésta pierde algo de su esencia. Sus trabajos en hormigón han sido reproducciones de sus tallas en piedra.

Ödön Koch, quien trabajó casi siempre en piedra, realizó unas magníficas esculturas en hormigón en varias ciudades de Suiza. En la superficie de sus esculturas deja grabado el dibujo de la madera natural empleada en el 
encofrado, cuidando el ancho de las tablas y generando éstas un rayado en la superficie, que acentúa la direccionalidad de los diferentes volúmenes de la composición.

En 1956, Francisco Somaini (Italia, 1926) comenzó a mezclar limaduras de hierro con el hormigón, produciéndose una pátina metálica, y obteniendo un curioso color a través de la oxidación.

Pero fue en México, en la década de los cincuenta, donde un grupo de escultores más utilizó el hormigón armado como material idóneo para sus obras, entre los que destacan Mathias Goeritz y Fernando González Gortázar.

Inevitablemente la utilización del hormigón fue adoptada por aquellos escultores que cambiaron las formas antropomórficas por las constructivas, la técnica de sustraer el material por la de adición y superposición de los diferentes elementos de una composición. Los conceptos de una nueva estética difundida por los constructivistas rusos, Bauhaus en Alemania y el grupo Stijl en Holanda abrieron nuevos caminos, pero hubieran sido las últimas composiciones del escultor Vantongerloo las más apropiadas para construirlas en hormigón.

Ángel Duarte (España, 1930) que trabaja fundamentalmente en conceptos matemáticos para sus formas, realizó en 1976, a las orillas del lago de Ginebra, en la ciudad de Pully, una escultura de hormigón de superficie paraboloide, que la gente llama "Despegue" por su aspecto de ingravidez, a pesar de su enorme peso.

En España es Eduardo Chillida quien más ha utilizado este material para sus obras monumentales. A su Sirena Varada de Madrid le siguieron otras en Guernica, Barcelona y Gijón.

Pero como quiera que generalmente estas obras, por su escala monumental, están situadas en el entorno urbano, quiero dedicar un espacio en este artículo a los trabajos de escultura en el espacio público.

\section{LA ESCULTURA Y EL ESPACIO PÚBLICO}

Las ideas progresistas, y por tanto democráticas, de sacar el arte de los museos, galerías y colecciones privadas a la calle por parte de las vanguardias de este siglo, cristaliza en que el escultor empiece a proyectar sus obras pensando en una escala apropiada para el medio urbano.

En 1920, Vladimir Tatlin proyecta su monumento a la III Internacional, que ha pasado a ser una obra señera del arte moderno y ejercicio de observación y estudio para todo escultor constructivista
En Alemania, los artistas de la Bauhaus no gustaron del concepto "arte en la construcción" que los arquitectos habían acuñado como el arte añadido a la construcción. Prefieren hablar de "arte en el espacio público".

Más tarde, en 1950 y en plena reconstrucción del país, el Parlamento Alemán destina el 1\% de la suma empleada en obras públicas a la ornamentación artística. Esto condujo a intervenciones de índole cosmético, pero no de índole quirúrgico y sólo en algunos casos se llegó a soluciones integradas.

El estilo Internacional de Arquitectura de acero y cristal, hace que el arquitecto prescinda del escultor como colaborador. Por otro lado, la evolución de la escultura (más lenta que en la arquitectura) que no se conforma con la instalación de una obra en la calle sin tener en cuenta el medio que la rodea, sino que aquí el escultor quiere involucrarse con todos los datos culturales de ese lugar, para luego dibujar pensando en ese entorno urbano, deja de colaborar con el arquitecto constructor de edificios para contribuir con su trabajo en el nuevo diseño del entramado urbano por el arquitecto urbanista.

Sus obras serán esculturas-construcciones de dimensiones importantes y que por su emplazamiento en el entramado urbano deben responder: a las condiciones del lugar, a la cultura que los engloba $y$, en ocasiones, a requisitos funcionales.

$\mathrm{Ni}$ que decir tiene que la escala aquí es un factor determinante; ésta es tan importante que la misma forma

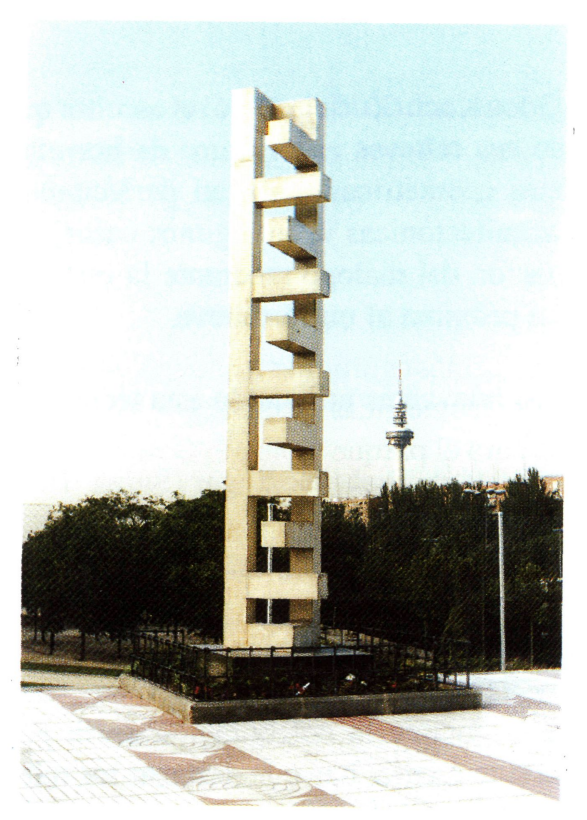

Fig. 1.- Homenaje a El Lissitzky. Jesús Molina, 1988. Hormigón armado 1x1x6 m. C/ Alcalá, puente de Ventas, 1992. Donación de F. C. ('. al pueblo de Madrid con motivo del "Madrid Capital Europea de la Cultura $1992^{\prime \prime}$. 
puede dar al traste con su cometido si la escala no está debidamente estudiada

En 1938, Constantin Brancusi realizó en Tirgu-Jiu, un pueblo de Rumania, un conjunto unitario de esculturas a lo largo de un kilómetro, con la Puerta del Beso, un gran obelisco y todo un conjunto de mesas con asientos que pueden usarse como mobiliario urbano. Constantin Brancusi (Rumania, 1876-1957).

En 1952, Isamu Naguchi(Los Angeles, 1904-1988) proyecta en Nueva York un parque infantil para el edificio de las Naciones Unidas, que no llegó a realizarse, pero sí se realizó en 1956 el jardín japonés en la sede de UNESCO en París.

En Suiza es Ödön Koch quien realiza, a partir de los años cincuenta, varias esculturas de hormigón armado en diferentes ciudades de su país; sus composiciones son ideales para utilizar este material.

En Alemania Otto Herbert Hajek (Alemania, 1927), trabaja sobre una zona peatonal de Frankfurt combinando sendas de color y volúmenes escultóricos de hormigón pintado. El quiere humanizar el medio ambiente, eligiendo el espacio público como campo de trabajo.

El escultor que más ha trabajado con hormigón sus obras es Mathias Goeritz, quizás porque también es uno de los artistas al que más le ha preocupado el espacio público. Este hombre, que nació en Alemania en 1915, fijó su residencia en México a partir de 1949. En 1957, junto con el arquitecto Luis Barragán, crearon uno de los espacios monumentales más importantes en la Ciudad de México, La Plaza de las Cinco Torres, un conjunto de cinco prismas regulares de base triangular, cuyas alturas oscilan de los 37 a los $57 \mathrm{~m}$. Quizás estas proporciones sirvan más para el disfrute visual desde lejos, conduciendo por sus alrededores, que como espacio para el ciudadano en el lugar de su emplazamiento

También en este pais Fernando González Gortázar (México, 1942), que además es arquitecto, dobla su interés por las composiciones geométricas realizadas en hormigón. En 1972, realiza para el parque Gonzalo Gallo de Guadalajara una imponente construcción formada por varios elementos minimalistas en forma de $\mathrm{Y}$ de $13 \mathrm{~m}$ de altura, en el que uno de los brazos se prolonga, llegando casi a la horizontalidad en una gran voladura, con un largo total de la escultura de $18 \mathrm{~m}$. En esta misma ciudad González levanta "La Torre de los Cubos", una composición modular de 30 cubos de hormigón prefabricado unidos entre sí por cables de acero, alcanzando una altura de $20 \mathrm{~m}$. A González le interesa dar al hormigón una textura fina, para lo que utiliza en el encofrado madera contrachapada cubierta de poliéster con fibra de vidrio; una vez desencofrados los pinta de blanco.
El hecho técnico de que un volumen cualquiera de hormigón haya tenido que ser moldeado, nos hace pensar que podemos repetir ese moldeo utilizando el mismo encofrado, con lo que el resultado será la obtención de varias reproducciones idénticas. Tanto en arquitectura como en la creación artística y en la fabricación de mobiliario urbano, esta técnica ha sido y es práctica habitual en la industria del hormigón

La composición modular, tanto en estudios sobre el plano como en tres dimensiones, ha sido uno de los capítulos más importantes del arte contemporáneo. Resulta curioso observar cómo una composición rica en conceptos estéticos queda determinada por la unión repetitiva de un sólo módulo, gracias a las leyes de geometría que juegan un papel importante en el movimiento espacial del módulo y en su ensamblaje. Dice Herber Bayer que "la realización de elementos prefabricados en arte no debe suponer la deshumanización del mismo" y si tenemos en cuenta que estos elementos trabajados en el taller deben ser más cuidados en su realización y precisión, el resultado final obedecerá más al programa impuesto por el artista.

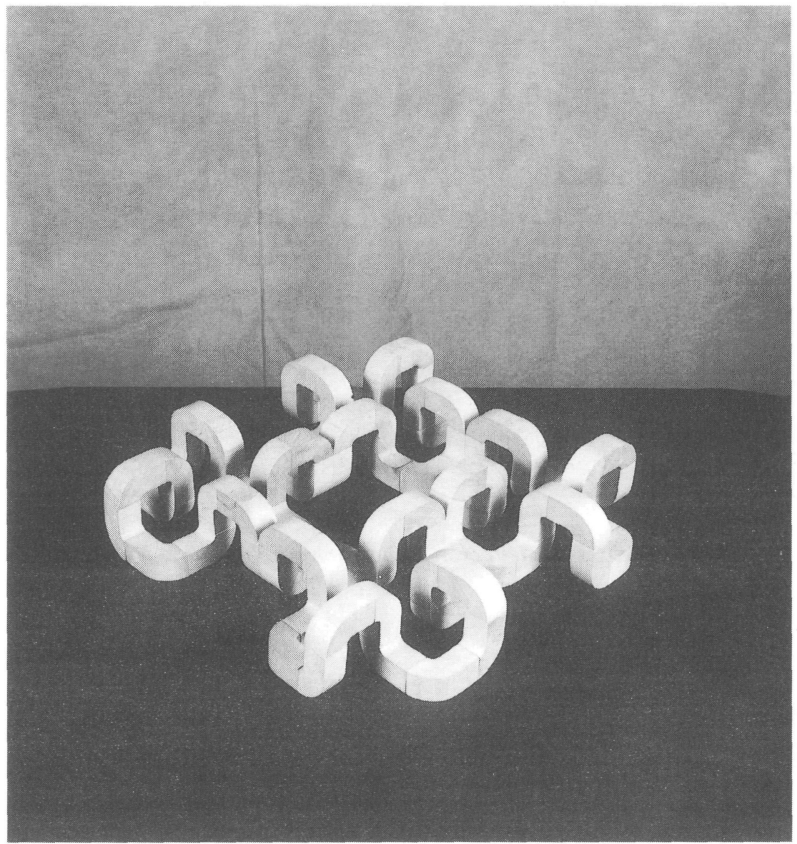

Fig. 2.- Laberinto. Construcción modular, utilizando un sólo módulo. Hormigón prefabricado. Jesús Molina, 1980.

Si el escultor ha elegido el espacio público como campo de trabajo, le preocuparán todos aquellos objetos que llenan la ciudad y que se ha dado en llamar mobiliario urbano, que si bien está en manos de grandes industrias alejadas del mundo del artista, son muchos los casos de objetos diseñados por éstos, y enlazando con lo dicho anteriormente sobre módulos repetitivos moldeados en hormigón, tomemos como ejemplo un banco de asiento de hormigón armado: habrá que moldearlo un sinfín de veces, lo que requiere un 
encofrado metálico que asegure el máximo de moldeados sin deformarse.

Pero hay un apartado en el conjunto de estos objetos que es el de aquellas construcciones dedicadas al niño como juegos infantiles. Grandes monstruos en los que el niño se introduce en sus entrañas para transitar todo su interior y asomarse por la gran boca, o graciosos y complicados laberintos que son el deleite de los chavales. Lo que aportan estas construcciones, que no son ni más ni menos que esculturas transitables, es la posibilidad de albergar en su interior un mayor número de niños, lo que hace más interactivo el juego, al mismo tiempo que ejerce una fuerte presencia con cualidades estéticas y referenciales en el lugar donde está situado.

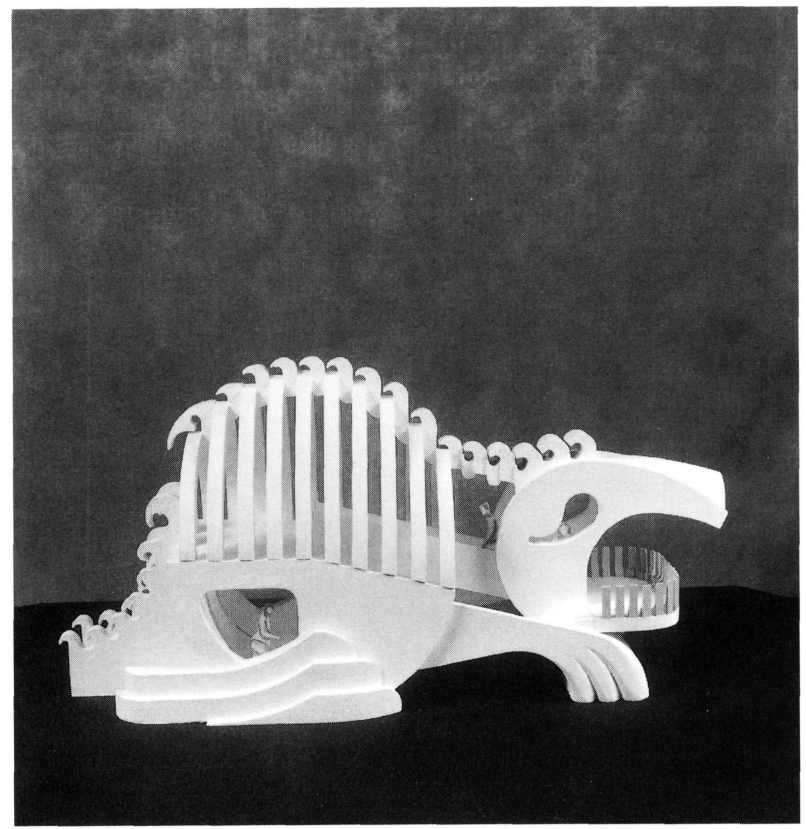

Fig. 3.- Dinosaurio. Construcción lúdica transitable para niños. Para construir en hormigón armado. 12,8 x 5,6 x 7,3 m. Jesús Molina, 1990.

En 1967, el escultor Michael Grossert y el pintor Theo Gerber ocuparon toda la superficie del patio de un colegio en Reinach, cerca de Basilea, con un sinfin de construcciones de hormigón pintado, creado un espacio laberíntico con graciosos desniveles, que obligan al niño a medirlos y salvarlos con su cuerpo.

Es indudable que el hormigón armado es asimilado como material por creadores de arte abstracto, quizás amantes de la arquitectura, apreciando una de sus cualidades constructivas: la articulación de la forma.

"Una forma articulada se ha de dar con nitidez, debe aprenderse incluso antes de que haya transmitido algún significado.

Por esa razón estan importante abstraer la forma, despojada de aquello que, por trivial, pueda ocultar su lógica y retirarle los significados habituales para dar cabida a otros nuevos" (Susane K. Langer. Feeling and Form. A Theory of Art. London, 1953).

- Sobre el carácter social del arte público en el entramado urbano:

"La ciudad es la consecuencia del deseo del hombre de reunirse y comunicarse con sus semejantes" Louis I. Kahn. Arquitecto (1901-1974).

Despojandoel término social de toda manipulación política, estas esculturas podemos verlas como construcciones, cuya calidad estética debe superar, por su mayor libertad de expresión y su innecesaria habitabilidad, a la arquitectura. Pero si al igual que en la arquitectura le añadimos un contenido de carácter social, esto, sólo puede ser entendido si estudiamos el espacio circundante, o lo que es lo mismo, el lugar donde se desarrolla la actividad diaria de los ciudadanos.

No importa que el ciudadano se siente, transite y trepe por estas obras. Deja de ser un objeto sagrado al que admirar y no tocar, para pasar a ser:

Un lugar de encuentro.

Un lugar de referencia.

Un espacio para disfrutar

Un lugar donde el ciudadano se aísla de lo cotidiano y abrumador de la arquitectura de la ciudad, dejándose envolver por una atmósfera que estimule y agite su sensibilidad.

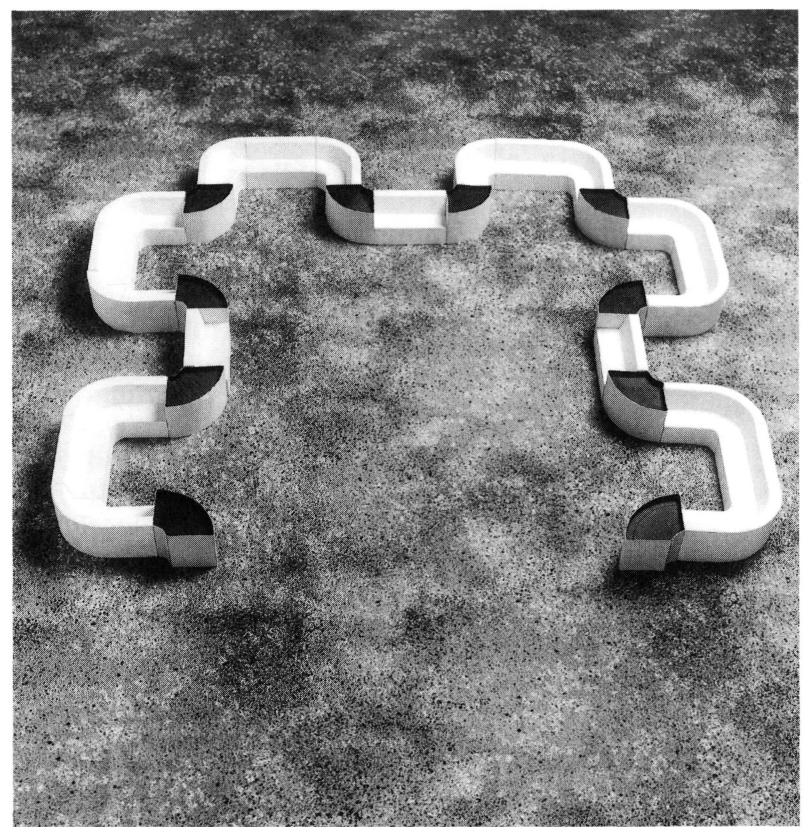

Fig. 4. Banco modular con jardinera. Hormigón prefabricado. Jesús Molina, 1980 


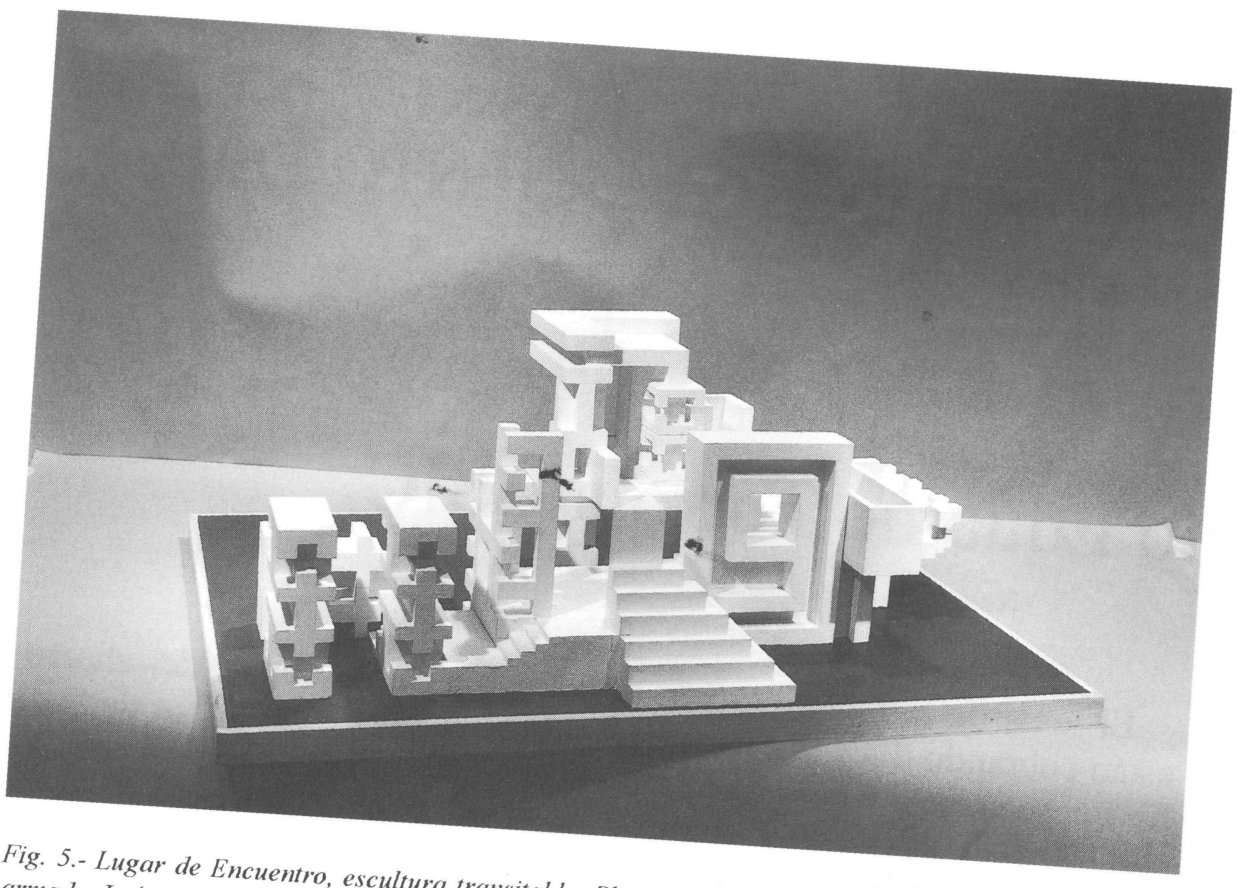

armado. Jesús Molina, 1993. 